\title{
Professions Susceptible to Automation; A Study on Automotive Sector Employees
}

\author{
Aylin Goztas \\ Full Professor at Ege University \\ Fusun Topsumer \\ Full Professors at Ege University \\ Mehmet Karanfiloglu \\ Research Assistant at Mustafa Kemal University
}

Ozlem Cosan

Ph.D. Candidate at Ege University

\begin{abstract}
The future of jobs has been a popular issue in the industry 4.0 process and digitization. Many of today's profession groups are at risk with automation in the digitalization process and most will be replaced to computerbased software and robots. By this concept, with Industry 4.0, we come up with whether the jobs are susceptible or non-susceptible to automation. According to researchers, jobs, where more routine and labor-intensive work is done, are categorized as group of jobs prone to automation, on the other hand jobs requiring human skills in which intellectual skills are used intensively, especially those that cannot be done through machines yet are categorized as group of jobs non-susceptible to automation. A recent Forrester Report predicts that by 2021, $6 \%$ of jobs in the US will be automated. In another study, it is predicted that $47 \%$ of the professions in the US will be unmanned during the automation process. By this study, a review of the literature on the susceptibility of the various professions to automation will be made and self-assessment of the automotive sector managers in İmir and the surrounding areas regarding their future professions will be studied through a descriptive study.
\end{abstract}

Keywords: Industry 4.0, Self-Assessment, Automotive Sector

\section{Introduction}

Future of the professions has become a current issue by the process of Industry 4.0. Despite the fact that Industry 4.0 has started to shape job's future, industry 4.0 will provide new opportunities for current positions according to some people for those who defend that everything would be better and there will be more need to people; the contrary, it is objected by some of those who are dystopian and defend that everything would be worse. Both opinions show that there would be an absolute change in anyhow and both sides come together on this idea.

Many positions in the banks became unnecessary by the existing of Automatic Teller Machine (hereinafter ATM). Thus, many working bank tellers have been unemployed due to fact that ATM's had taken their place. Logically, after that unemployment, we must have seen fewer workers in the banks. Conversely, after ATM's have been invented results show that the number of the tellers and the other employees became increased instead of drop. Furthermore, people need for the banks gradually increased after ATM's have been placed, this led many other job positions. These facts, revealed in a recent book by Boston University economist James Bessen, raise an intriguing question: what are all those tellers doing, and why hasn't automation eliminated their employment by now? If you think about it, many of the great inventions of the last 200 years were designed to replace human labor. Tractors were developed to substitute mechanical power for human physical toil. Assembly lines were engineered to replace inconsistent human handiwork with machine perfection. Computers were programmed to swap out error-prone, inconsistent human calculation with digital perfection. These inventions have worked. We no longer dig ditches by hand, pound tools out of wrought iron or do bookkeeping using actual 
books. And yet, the fraction of US adults employed in the labor market is higher now in 2016 than it was 125 years ago, in 1890 , and it's risen in just about every decade in the intervening 125 years.

David Autor, on a stage talk on TEDx, has explained this growth in business with O-Ring and Never Get Enough principles. O-Ring principle defines the types of work we do, Never Get Enough principle determines how many jobs there actually are. Most of the work that we do requires a multiplicity of skills, and brains and brawn, technical expertise and intuitive mastery, perspiration, and inspiration in the words of Thomas Edison and that bring us to the second principle: never get enough. In 1900, 40 percent of all US employment was on farms. Today, it's less than two percent. He questions that why there are so few farmers today. It's not because we're eating less. A century of productivity growth in farming means that now, a couple of million farmers can feed a nation of 320 million. This grand progress means there are only so many 0 ring jobs left in farming. It can be clearly seen as technology can eliminate jobs however farming is only one example. According to David Autor, it's unwise to say there's nothing to worry about. This can be understood incorrectly. If the US had not invested in its schools and in its skills a century ago with the high school movement, we would be a less prosperous, a less mobile and probably a lot less happy society. But it's equally unwise to say that our fates are sealed. That's not decided by the machines. It's not even decided by the market. It's decided by us and by our institutions (Autor, 2017).

In the light of all this information, we can see that it necessary to define how the organizations assess themselves and take place to deal with the phase in Industry 4.0 process. Therefore, it is of great importance that to be understood the processoriented self-assessment of organizations.

\section{Literature Review}

Concerns about the impact on the workplace of the industry 4.0 process are not new. If the concerns are justified, the seats of the constructions working in this area will be discharged by transferring many business fields to the computers in the next few years. The emergence of evidence that computers in the last few years have replaced a large number of jobs, especially accountants, cashiers and telephone operators, has rekindled this debate (Schwab, 2017). By Industry 4.0, robotic systems will take place by means of machines can communicate with each other in factories. Here in after, all the organizational structures and the way of working for companies will be fundamentally changed according to Schwab. It is debated that whether all the process steps and work style would change from marketing to sale department, production to place and rest departments. There will be new concepts that get into our daily life such as; robotics, autonomous transportation, artificial intelligence, learning machines, advanced materials, biotechnology and genome science. While some professions would be gone, there will be new positions that we never heard of, and some profession will be only updated to the future's conditions. Farther, human recourses departments will be affected by those changes that evolve into the new human-machine oriented process.

Technologies grow so fast that innovations which have been approved by the companies would take place the old fashion machines in rapidly by new technologies arrives into the business. Those new machines and systems are connected to the internet (IoT: Internet of Things) by inner wireless connection plugs so that they can talk to each other and manage the process in dark factories. It can also be seen in our high-tech design houses with new applications through interior machines such as; automatic curtains, lights, bed, coffee machines... etc. In these houses, the owner can control and secure the whole house facilities with a smart-phone application.

The velocity that is one of the most important factors of Industry 4.0, is a key factor of increasing concerns in this regard. Depth and extensity can be sorted as the other factors, which brought us to see there are many radical changes occurs and all the systems re-structured from head to toe. From this point, it is possible to say that this powerful force can put all the professions' process forward and re-organize them in differentiated dimensions. However, it is still not clear to see that how further this can go and in what amount of time.

To handle this, first of all, it shall be studied that how deterioration and automation of technology can substitute labor with capital and how taking workers to be unemployed and/or to force them to use their skills on other positions emerges a devastating effect. Secondly, this destructive effect is accompanied by a developer effect; the demand for new products and services that are increasing and bringing new professions, jobs, and even sectors.

Thus, two different results can be handled within this period; there is one side who believes to the happy end and the other side who believes that this will create massive technological unemployment. A qualitative change in current labor is vital 
and labor requirement will continue increasingly for those who defend the happy-end scenario. Those who advocate reverse argue that this change is not possible within this "speed" and that many lives will negatively affect this issue.

In other respects, each technologic development brings a new opportunity while abolishing some of the industrial branches as it can be seen through the historical process. Therefore, human resources could be appraisable for another available position when it is not essential on the current position. For example, thousands of labors who had been working in the agricultural industry have now replaced with machines. At the beginning of the 19th century, agricultural workers in the US were about 90 percent of the total workforce, but today is about 2 percent (Schwab, 2017). Yet, the necessity of labor in different places, especially in the service industry, has caused these people to migrate from their villages to the cities and to exist in different branches of business. Therefore, techno-optimists argue that in the future, the automation process will replace the business lines that are available today with unique positions.

Many different working categories, especially those requiring mechanical repetition and precision hand labor, have already been involved in automation. A recent Forrester Report predicts that by $2021,6 \%$ of jobs in the US will be automated. In another study, it is predicted that $47 \%$ of the professions in the US will be unmanned during the automation process. As technological developments tolerate, many of today's professions will eventually become partial or completely liable to automation such as analysts, doctors, journalists, accountants, insurers, and librarians ... etc. The current situation shows that: As it seems through the Oxford Martin Technology and Employment Program predicts, today only 0.52 percent of the American labor force is working in sectors that did not exist at the beginning of the century. However, this ratio was about 8 percent in the 1980s and 4.5 percent in the 1990s. A new report from the US Bureau of Economic Census in which sheds on an interesting relationship between technology and employment reinforces it even more. The report indicates that productivity of innovations on informatics' systems and other disruptive technologies has increased by replacing existing workers rather than creating new products that will need more labor-time (Christensen, Raynor, \& McDonald, 2015).

Two researchers from the Oxford Martin School, Economist Carl Benedict Frey and Machine Learning Specialist Michael Osborne digitized the potential impact of technological innovation on employment by sorting 702 different jobs into the probability of being liable to automation, the least sensitive to automation risk, and the most sensitive to risk. As can be seen in the table, the most and least susceptible occupations are listed in automation.

\section{Table 1. The Least and the Most Susceptible Professions to Automation}

\begin{tabular}{ll}
\hline \multicolumn{2}{l}{ The Most Susceptible to Automation } \\
\hline Possibility & Jobs \\
\hline 0,99 & Telemarketers \\
0,99 & Tax Consultants \\
0,98 & Insurance Expert \\
0,98 & Referee and Other Sport Workers \\
0,98 & Law Reporter \\
0,97 & Waiters at Cafe and Restaurants \\
0,97 & Estate Agent \\
0,97 & Farm Workers Middlemen \\
0,96 & Secretary, Managerial Assistants \\
0,94 & Deliverer \\
The Least Susceptible to Automation \\
\hline Possibility & Jobs \\
\hline 0,0031 & Mental Health and Substance Addiction Social Workers \\
0,0040 & Choreographers \\
0,0042 & Doctors and Surgeons \\
0,0043 & Phycologists \\
0,0055 & Human Resource Managers \\
0,0065 & Computer System Analysts \\
0,0077 & Anthropologists and Archeologists \\
0,0100 & Marine Engineers and Naval Architects \\
0,0130 & Sales Managers \\
0,0150 & General Managers \\
\end{tabular}

Source: Klaus Schwab, (2017). Dorduncu Sanayi Devrimi (The $4^{\text {th }}$ Industrial Revolution), Optimist, Istanbul. P:48 
On the other hand, it is claimed that some new professions will come out. According to the Industry 4.0 Platform in Turkey some professions that will be needed in the coming years are as follows (Eger, 2017):

- Industrial Data Science

- Data Security Expertise

- Robot Coordination

- Network Development Engineering

- IT / IOT Solution Architecture

- 3-D Printer Engineering

- Industrial Computer Engineering / Programming

- Industrial User Interface Designer

- Cloud Computing Expertise

- Wearable Technology Designers

The other issue is that automation will not be completed overnight, and key factors will in hence the pace and extent of its adoption. Five factors affecting pace and extent of adoption (McKinsey Global Institute, 2017) are as follows:

Technical Feasibility Technology has to be invented, integrated, and adapted into solutions for specific case use,

Cost of Developing and Deploying Solutions Hardware and software costs,

Labor Market Dynamics The supply, demand, and costs of human labor affect which activities will be automated,

Economic Benefits Include higher throughput and increased quality, alongside labor cost savings,

Regulatory and Social Acceptance Even when automation makes business sense, adoption can take time.

First is technical feasibility, since the technology has to be invented, integrated and adapted into solutions that automate specific activities. Second is the cost of developing and deploying solutions, which affects the business case for adoption. Third are labor market dynamics, including the supply, demand, and costs of human labor as an alternative to automation. Fourth are economic benefits, which could include higher throughput and increased quality, as well as labor cost savings. Finally, regulatory and social acceptance can affect the rate of adoption even when deployment makes business sense. Taking all of these factors into account, we estimate it will take decades for automation's effect on current work activities to play out fully. While the effects of automation might be slow at a macro level within entire sectors or economies, they could be quite fast at a micro level, for an individual worker whose activities are automated, or a company whose industry is disrupted by competitors using automation (McKinsey Global Institute, 2017).

Another study by McKinsey Global Institute "What the future of work will mean for jobs, skills, and wages" is focusing on five questions shown below. The results reveal a rich mosaic of potential shifts in occupations in the years ahead, with important implications for workforce skills and wages. Our key finding is that while there may be enough work to maintain full employment to 2030 under most scenarios, the transitions will be very challenging matching or even exceeding the scale of shifts out of agriculture and manufacturing we have seen in the past (Manyika, et al, 2017).

What impact will automation have on work?

What are possible scenarios for employment growth?

Will there be enough work in the future?

What will automation mean for skills and wages?

How do we manage the upcoming workforce transitions? 


\section{Fig 1. Automation Will Have a Far-Reaching Impact on The Global Workforce}

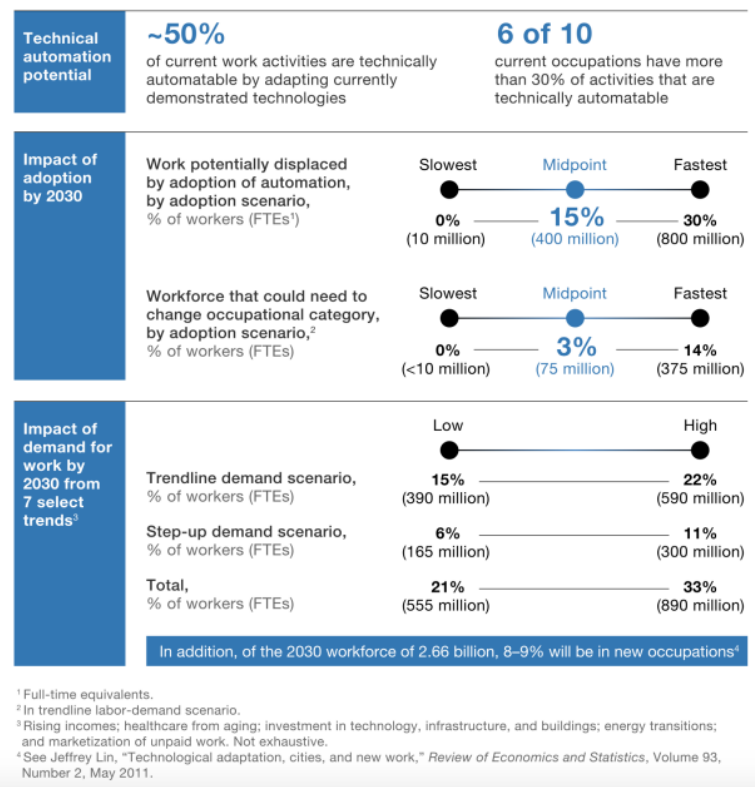

\section{Source: McKinsey Global Institute Analysis}

From a different perspective on the same subject; it is necessary to take a look at positions at this time. In the future, examine the most likely jobs that computers will take and the positions that are expected to depend on labor for a longer period of time:

\section{Fig 2. Automation Potential Based on Demonstrated Technology of Occupation Titles in US}

Automation potential based on demonstrated technology of occupation titles in the United States (cumulative)

\begin{tabular}{l} 
Example occupations \\
$\begin{array}{l}\text { Sewing machine operators, } \\
\text { graders and sorters of } \\
\text { agricultural products }\end{array}$ \\
Stock clerks, travel agents, \\
watch repairers \\
\hline $\begin{array}{l}\text { Chemical technicians, } \\
\text { nursing assistants, } \\
\text { Web developers }\end{array}$ \\
\hline $\begin{array}{l}\text { Fashion designers, chief } \\
\text { executives, statisticians }\end{array}$ \\
\hline Psychiatrists, legislators
\end{tabular}

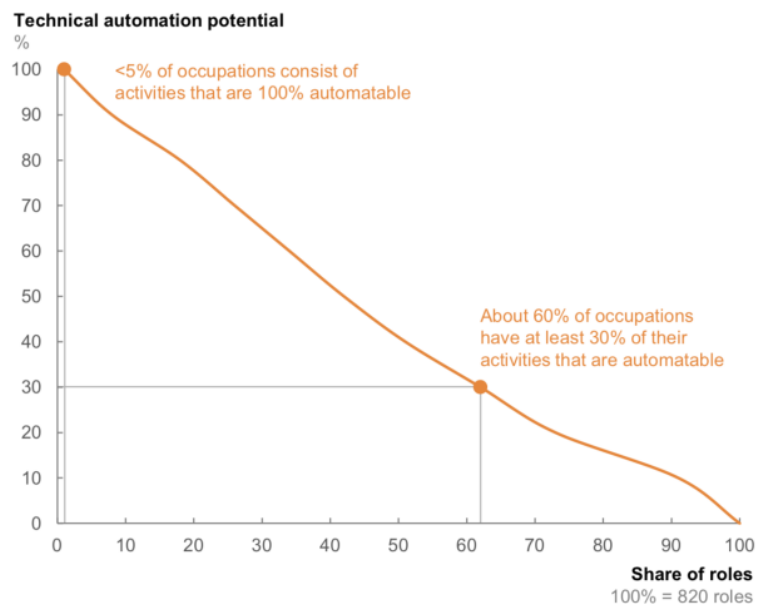

1 We define automation potential according to the work activities that can be automated by adapting currently demonstrated technology.

SOURCE: US Bureau of Labor Statistics; McKinsey Global Institute analysis

Source: McKinsey Global Institute Analysis 
Fig 3. Three Categories of Work Activities Have Significantly Higher Technical Automation Potential

Three categories of work activities have significantly higher technical automation potential

\begin{tabular}{|c|c|c|c|c|c|c|c|}
\hline & $\begin{array}{l}\text { Time spe } \\
\%\end{array}$ & nt on activi & that can b & atomated by & dapting curre & $y$ demonstrate & technology \\
\hline & & & & & & & 81 \\
\hline & & & & & 64 & 69 & \\
\hline & & 18 & 20 & 26 & & & \\
\hline Time spent & 7 & 14 & 16 & 12 & 17 & 16 & 18 \\
\hline $\begin{array}{l}\text { occupations } \\
\%\end{array}$ & Manage $^{1}$ & Expertise $^{2}$ & Interface ${ }^{3}$ & $\begin{array}{l}\text { Unpredict- } \\
\text { able } \\
\text { physical }^{4}\end{array}$ & $\begin{array}{c}\text { Collect } \\
\text { data }\end{array}$ & $\begin{array}{c}\text { Process } \\
\text { data }\end{array}$ & $\begin{array}{l}\text { Predictable } \\
\text { physical }^{5}\end{array}$ \\
\hline Total wages & 596 & 1,190 & 896 & 504 & 1,030 & 931 & 766 \\
\hline & & & & & $\begin{array}{l}\text { Most } \\
\text { susceptible } \\
\text { activities }\end{array}$ & $\begin{array}{l}51 \% \\
\text { of total } \\
\text { employment }\end{array}$ & $\begin{array}{l}\$ 2.7 \text { trillion } \\
\text { in wages }\end{array}$ \\
\hline
\end{tabular}

1 Managing and developing people.

2 Applying expertise to decision making, planning, and creative tasks.

3 Interfacing with stakeholders.

4 Performing physical activities and operating machinery in unpredictable environments.

5 Performing physical activities and operating machinery in predictable environments.

NOTE: Numbers may not sum due to rounding.

\section{Source: McKinsey Global Institute Analysis}

Here, serial production jobs are expressed as "predictable physical" which is simple operator tasks not based on mastery in factories. "Unpredictable physical" means to not based more on hand job that done in regular, standard places and not always done in the same way. As you can see, jobs that are predictable, are physical work done in specific environments, are data processing and data collection jobs have the highest potential for automation in future. The managerial and decision-making expertise positions are safe areas in this respect.

According to the research, automation transformation process depends on sectors, positions and countries conditions. But jobs that can be done with computers at a high rate are a global concern of 1.2 billion people with their salary of 14.6 trillion dollars.

The two factors that will have the most impact on automation are the productivity and labor market. The following chart helps us to see the big difference between what is now and what is expected in the next 50 years: 
Fig 4. Technical Potential for Automation Across Sectors Varies Depending on Mix of Activity Types

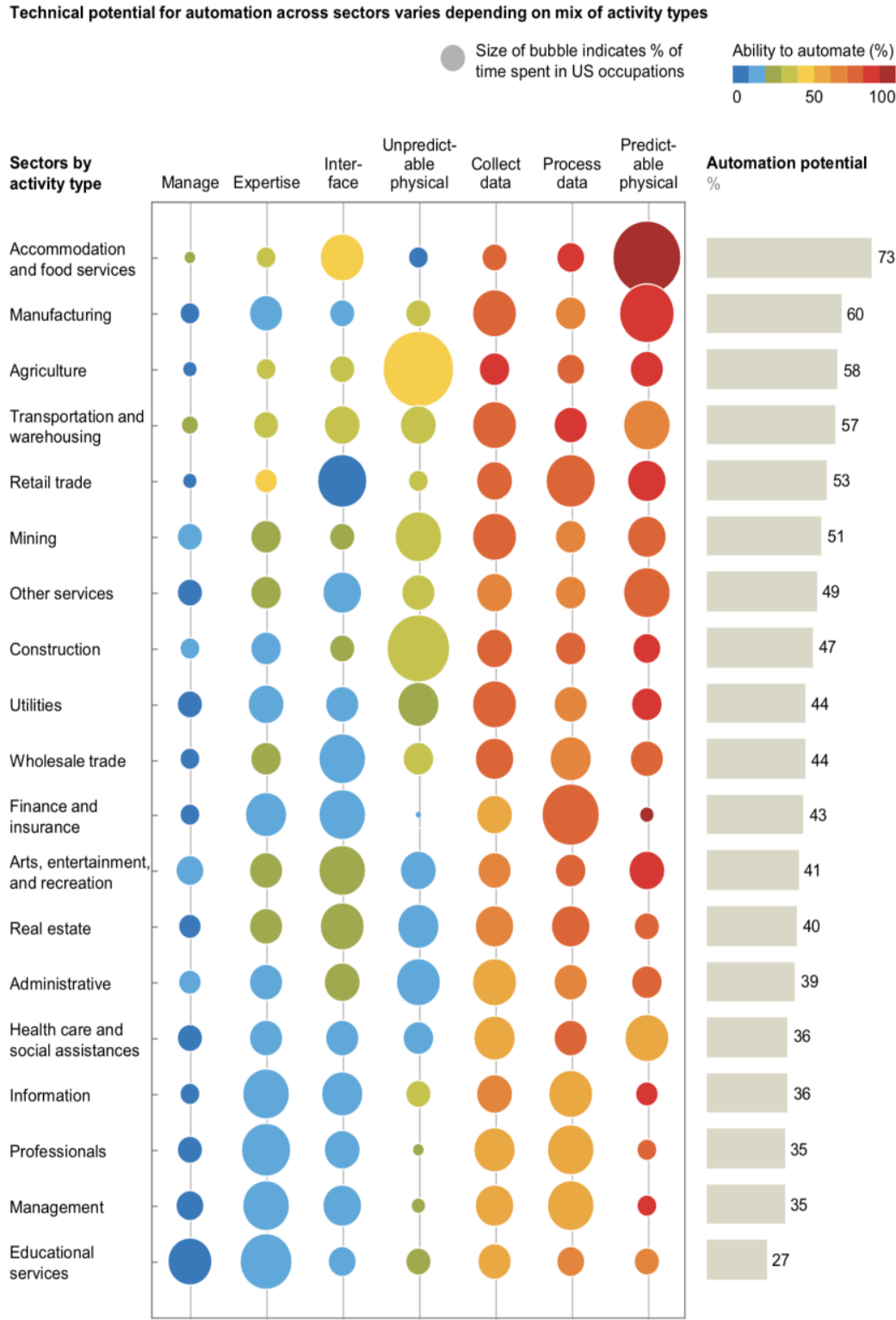

Source: McKinsey Global Institute Analysis

\section{Methodology}

The aim was to investigate and find out about the automotive sector managers in Izmir and the surrounding areas regarding their future professions. According to our literature review, there were a few specific studies conducted related to professions' automation in the US but no research in Turkey. Because of that reason, due to exploratory nature, in-depth interviews were chosen as the research method (Yin, 1989; Sasi \& Arenius, 2008). Qualitative methods should be used to 
clarify social issues in order to get deeper information (Hill, McGowan, \& Drummond, 1999; Hoang \& Antoncic, 2003; Jack, Dodd, \& Anderson, 2009). Purposive sampling approach was used and 10 participants were selected from the members of automotive sector managers and/or company owners. Series of 10 interviews were made with the participants. The questions of interviews were about self-assessment of Industry 4.0 process of companies and profession's future. Collected data were inductively analyzed, network patterns were discovered. The main limitation is our sample size so it is not enough to generalization, and the company types. Working with different sectors and more samples are our future objectives to improve our study.

\section{Findings}

According to quotas derived from transcripts, we found four main themes.

\section{The first theme is Lower Investment Requirements and Securing Current Investments.}

The hardware and software investments in applications made for individual machines and facilities can be provided at optimum costs in virtue of the modular structure reached and standardization provided in automation systems in which functions and capabilities of it are constantly increasing. Furthermore, it does not constitute an obstacle to modernization and capacity building investments in facilities, existing automation infrastructure despite changing technologies, in virtue of the compatibility that has been developed over the years.

According to interviews, we have observed that process of Industry 4.0 is being seen as uncomplicated for adaptation. Generally, managers emphasized that transforming all the steps of the company into the automation is requiring lower investment due to their current working structure. The infrastructure of the city such as the internet has been evaluated as an only possible obstacle.

On the other hand, lowering their budget on the process means to them as more employment possibility due to the fact that it is mostly believed that it is not possible to operate all those new systems without their current employees in this new process. One of the participant managers expressed this as: "We are planning to adapt our location (workplace) fully automated systems in a very little soon without unemployed any workers we have. Because we are aware of experience they have and this experience will provide us to operate those systems smoothly..." The other emphasized that it also secures their investments by holding current employees as "As we are approaching the new era of Industry, we all know that this cannot be handled without the support of our current employees, they all know how to systems work, and how to operate them in an urgent case. We are in a place that always facing with some connection problems, thus leaving all those systems without any control will cause lots of problems. Therefore, we'll keep our employees to seek all those processes. We have all started to train our employees according to this new industrial revolution already..."

\section{The second theme is Productivity and Quality Enhancement.}

Integration in automation systems occurs in three different dimensions. In order to refer the high level of integration and the benefits that it will provide, whole communication facilities of an automation system, engineering tools, and data management must constitute an integrity. For different processes, it is possible to obtain a real productivity increase and service quality in the facilities with standardized and coordinated engineering tools and operator interfaces. Product and production quality can be monitored and reported in real time, furthermore, it can be easily shared between different units and businesses between production and management levels in favor of an integrated data management implementation. In virtue of reliable data and information that can be reached rapidly, product and production quality can be controlled on a global scale.

During the interviews, managers mostly emphasized the same idea by their words constantly such as "...providing quality...", "...its quality-oriented process...", "...provides quality ...", "...quality that is provided by...". Thus, we can say that the way their approaching the subject was about quality enhancement. They also stress that new process will provide many productivities with their employee's support. Almost all the managers expressed their opinions according to this as: "We all know professions will be affected by these process, but it will provide many other opportunities as well. With the new Industrial Revolution, if we can completely success to adapt to it, it will provide us a quality increase...", "Our profession will effect of course, but we do not plan any unemployment now, in the future as well. Because we know that our productivity with its quality-oriented process will be increased and this will not be organizable without our labor force..." 
Besides, today automation systems and developments in information technology allow the production process can interlock by ERP systems through the Manufacturing Execution Systems (MES) with horizontal integration. In this wise, there are examples that can be reduced up to $40 \%$ on inventory costs in the supply chain, with electronic connections availability.

\section{The third theme is The Ability to Deliver New Products Faster and Shorter Engineering Times.}

Modular structures of automation systems are supported by the necessary simulation models would be possible to conduct simultaneously with process engineering and to simplify automation engineering. Integrated automation platforms shared by many applications, achieve significant integration problems in projects and reduce the total engineering time in the application. In favor of Component-Based Automation ( $\mathrm{CbA})$, from material input to production processes and all kinds of engineering tools necessary for final products and facility modules can share the same platform.

In order to express this situation managers mainly said that it was possible to accelerate the ability to deliver new products by new industrial structure so that their employees can shorter their engineering times. A manager said that in this way: "...The production line we have is facing several problems due to it is half-automated architecture. When we complete the full automation, employees will be able to shorten their engineering timing." Another, an owner, said it was also facilitating and simplify their employees' jobs as: "Well, the new automation systems will bring new facilities that our employees can go with it. It will be a lot easier than it was for them to work. The operation will go on the cyber-systems, but to maintenance, them, control or check them if they were working properly we still need them..."

\section{The fourth theme is Complementary Solutions and Services.}

Despite all their sophistication, only automation systems and information technologies themselves may not be able to provide expected benefits. There is also a need for technical services to support all of these; intensive process experience, healthy logistics solutions, and appropriate energy infrastructure to be able to get fully expected benefits. These elements must also be taken into consideration by companies that offer products and systems towards the automotive industry in the electricity-electronics sector. Productivity in production, quality, and flexibility are required for almost every manufacturer within the diversity of brands and models in automotive, the intensifying and globally competitive environment. Herewith, all the manufacturers in the sector including the automotive supplier industry try to provide a competitive advantage by focusing on outsourcing by optimizing material flows and establishing modern energy management systems where they are inadequate or technical services where they have a cost advantage.

By this theme, we can say managers we interviewed all agree on keeping their employees despite the fact that they all believe that professions requirement will be re-organized to supply complementary solutions and services. According to the expression we analyzed, we could be seeing that current positions need might change in the future automation-oriented process according to managers thoughts, however, they plan to replace or change their employees' positions in order to keep their companies operatable. Their ideas rely on their believes that their employees are the only factor that can handle their companies during the Industry 4.0 adaptation process.

As an example, to demonstrate this, an owner of a company expressed that: "Well, unemployment in this process due to we replace the labors with machines is not logic I think. Because I personally know that without their experience we wouldn't be able to supervise the system. We will absolutely need new employees for the new positions but what we plan is to train the employees we have for that position that they can handle, but for the other positions we might need such as system engineer we will, of course, deploy it from outsource..."

\section{Conclusion}

As we can see, the future of the professions prone to change it anyhow. The jobs can differentiate such as operator, an untrained and unskilled labor or a housekeeper in a hotel. These are some of the things that are believed to be the most remote of learning opportunities, both material and intellectual, as well as time-consuming. According to some managers, it's not about a diploma or a monetary opportunity, but a learning desire and enthusiasm makes the difference. Most of the positions will be automated sooner or later, and unfortunately, some of the tasks are to be terminated. Naturally, new structure expects labor to be prone to data collection, open to learning.

Conversely, to look through another perspective, we can say that for those who do the above-mentioned kind of work in the digital age, they actually have more opportunities than ever before. There are endless possibilities even for a housewife to do digital marketing, reach out to other countries to connect someone or build a blog. As a matter of fact, it is necessary 
to have certain knowledge even to see that these possibilities exist. This fact also needs to be thought over; the world manages money and automation mean ability to do the same job cheaper and in more accurate and more predictable way. This transformation is not something that a person, group or country can manage, nevertheless, it is being seen as a general situation of the new world order. It is absolutely necessary to see what will happen in the next 30 years and prepare both ourselves and our institutions for it.

The Digital Future of Work Summit in New York in 2017; was about the digital future of business. According to the summit, whether for an employee, a young person in your 20s who will be assigned to working life or a child who has just started a primary school, there is an absolute need to be skilled, well-educated. The outputs from the summit are listed as follows:

- Learning to learn will be one of the most important competencies,

- Career paths will be much vaguer,

- Self-Learning ability has importance,

- A closer relationship with the machines is a must,

- It is necessary to think analytically and creatively,

- Being open to new opportunities,

- $\quad$ Ability to use new applications, be familiar with coding and sensor technologies.

Consequently, as it can be understood, this study regards to professions susceptible to automation shows that automotive industry managers and owners prone to have their employees as in the same position for the new industrial process or replace them to new positions by training them. In this study, participants interviewed, the automotive sector managers and owners, are from Izmir Aegean Industrial Region, and are working a different part of automation works, thus, these factors have been effective on results. In order to increase the validity and reliability of the study, we ought to increase the number of samples from different parts of Turkey. Therefore, we must state that we believe further research in the light of this study will give more general results.

\section{References}

[1] Autor, D. (Director). (2017). Will automation take away all our jobs? at TEDx [Motion Picture].

[2] Christensen, C. M., Raynor, M. E., \& McDonald, R. (2015, December). What is Distruptive Innovation? Harvard Business Review.

[3] Eger, E. (2017, December 18). Endüstri 4.0 ile Birlikte Gelecek 10 Yeni Meslek. Retrieved from Turkiye'nin Endüstri 4.0 Platformu: http://www.endustri40.com/endustri-4-0-ile-birlikte-gelecek-10-yeni-meslek/

[4] Frey, C. B., \& Osborne, M. A. (2013, September 17). The Future of Employment: How Susceptible Are Jobs To Computerisation? Oxford Martin School, pp. 1-72.

[5] Hill, J., McGowan, P., \& Drummond, P. (1999). The development and application of a qualitative approach to researching the marketing networks of small firm entrepreneurs. Qualitative Market Research, 2, 71-81.

[6] Hoang, H., \& Antoncic, B. (2003). Network-based research in entrepreneurship: a critical review. ournal of Business Venturing, 18, 165-187.

[7] Hofstede, G. J., \& Minkov, M. (2010). Cultures and Organizations: Software of the Mind. McGrawHill, Third Revised Edition, ISBN 0-07-166418-1.

[8] Jack, S., Dodd, S. D., \& Anderson, A. R. (2009). Change and the development of entrepreneurial networks over time: a processual perspective. Entrepreneurship and Regional Development, 20(2), 125-159.

[9] Kocyigit, M. (2017). Digital Halkla İliskiler ve Online Kurumsal Itibar Yonetimi. Konya: Egitim Kitapevi.

[10] Manyika, J., Lund, S., Chui, M., Bughin, J., Woetzel, J., Batra, P., . . Sanghvi, S. (2017). What the future of work will mean for jobs, skills, and wages. McKinsey\&Global. 
[11] McKinseyGloballnstitute. (2017). A Future That Works: Automation, Employment, and Productivity. McKinsey\&Company.

[12] Sasi, V., \& Arenius, P. (2008). International new ventures and social networks: Advantage of liability? European Management Journal 26, 400-411.

[13] Schwab, K. (2017). Dorduncu Sanayi Devrimi (The Fourth Industrial Revolution). Istanbul: Optimist. Retrieved from http://danismend.com/kategori/altkategori/musteri-iliskileri-yonetimi/

[14] Yin, R. K. (1989). Case Study Research: Design and Methods. Beverly Hills.: Sage Publications Ltd.

[15] Websites

[16] https://www.oxfordmartin.ox.ac.uk/downloads/academic/The_Future_of_Employment.pdf

[17] https://www.mckinsey.com/mwg-internal/de5fs23hu73ds/progress?id=-E2Mmj4ZGseXEpFLOggzsvFqMnrZJ_EPCFpP408qzE,

[18] https://www.mckinsey.com/global-themes/future-of-organizations-and-work/what-the-future-of-work-will-meanfor-jobs-skills-and-wages\#part 3

[19] https://learndigital.withgoogle.com/dijitalatolye?\&ds_kid=43700019378251546\&gclid=CjwKCAiAvf3RBRBBEiw AH5XYqKVgFrOAWATIDIb8QB08Dv4VLZJVmzZrABDC90bkyOAWWPW8bx_d1BoCtwUQAvD_BwE\&dclid= CMnYnKrXpNgCFUYgOwodmegOYw

[20] https://www.mckinsey.com/ /media/mckinsey/business \%20functions/mckinsey\%20digital/our\%20insights/whe re\%20machines $\% 20$ could\%20replace $\% 20$ umans $\% 20$ and $\% 20$ where $\% 20$ they $\% 20$ cant/sectorautomation.ashx

[21] http://digitalfutureofwork.com

[22] https://poyrazruzgari.com/2017/12/25/otomasyon-bize-ne-yapacak/

[23] https://www.onetcenter.org/database.html

[24] https://www.mckinsey.com/global-themes/future-of-organizations-and-work/what-the-future-of-work-will-meanfor-jobs-skills-and-wages\#part\%203

[25] https://www.mckinsey.com/ /media/McKinsey/Global\%20Themes/Future\%20of\%20Organizations/What\%20th e\%20future\%20of\%20work\%20will\%20mean\%20for\%20jobs\%20skills\%20and\%20wages/MGI-Jobs-LostJobs-Gained-Report-December-6-2017.ashx 